Marquette University

e-Publications@Marquette

$10-2015$

\title{
Treatment Response in Couple Therapy: Relationship Adjustment and Individual Functioning Change Processes
}

Lynne M. Knobloch-Fedders

Marquette University, lynne.knobloch-fedders@marquette.edu

William M. Pinsof

Claudia M. Haase

Follow this and additional works at: https://epublications.marquette.edu/psych_fac

Part of the Psychology Commons

\section{Recommended Citation}

Knobloch-Fedders, Lynne M.; Pinsof, William M.; and Haase, Claudia M., "Treatment Response in Couple Therapy: Relationship Adjustment and Individual Functioning Change Processes" (2015). Psychology Faculty Research and Publications. 358.

https://epublications.marquette.edu/psych_fac/358 
Marquette University

\title{
e-Publications@Marquette
}

\section{Psychology Faculty Research and Publications/College of Arts and Sciences}

This paper is NOT THE PUBLISHED VERSION; but the author's final, peer-reviewed manuscript. The published version may be accessed by following the link in th citation below.

Journal of Family Psychology. Vol. 29. No. 5 (October 2015); 657-666). DOI. This article is (C) American Psychological Association and permission has been granted for this version to appear in ePublications@Marquette. American Psychological Association does not grant permission for this article to be further copied/distributed or hosted elsewhere without the express permission from American Psychological Association.

\section{Treatment Response in Couple Therapy: Relationship Adjustment and Individual Functioning Change Processes}

\author{
Lynne M. Knobloch-Fedders
}

The Family Institute at Northwestern University;

William M. Pinsof

The Family Institute at Northwestern University

Claudia M. Haase

School of Education and Social Policy and Department of Psychology, Northwestern University

Acknowledgement: We thank Tara Latta, Erin Staab, and Richard Zinbarg for their assistance with this study.

Satisfaction with an intimate relationship is strongly associated with the mental health of both partners (for review, see Whisman \& Baucom, 2012). Relationship distress has been linked to numerous psychological disorders -including mood, anxiety, and substance problems (Whisman, 2007) - as well as impairments in physical health, work performance, and social functioning (Whisman \& Uebelacker, 2006). This co-occurrence of relational and individual pathology has been 
demonstrated both cross-sectionally and longitudinally (e.g., Davila, Karney, Hall, \& Bradbury, 2003; Villeneuve et al., 2014; Whisman, Uebelacker, \& Weinstock, 2004).

Although many outcome studies have documented the effectiveness of couple therapy in treating both relationship distress and individual pathology (for review, see Baucom, Belus, Adelman, Fischer, \& Paprocki, 2014; Baucom, Shoham, Mueser, Daiuto, \& Stickle, 1998), these studies have not evaluated the progression of change over time. Typically, outcome studies assess couples at pre- and posttreatment only, making it impossible to determine whether improvement occurs gradually but steadily or if it follows a more uneven course, with rapid periods of change early or late in treatment. A more detailed understanding of change processes is necessary to improve the effectiveness of couple treatment (Doss, Rowe, Carhart, Madsen, \& Georgia, 2011).

There is also a pressing need for couple therapy change process research conducted within realworld treatment-delivery settings. Because few intervention studies have been conducted in applied clinical settings, existing research on couple therapy suffers from low external validity (Lebow, Chambers, Christensen, \& Johnson, 2012). Wright, Sabourin, Mondor, McDuff, and Mamodhoussen (2007) evaluated methodological features such as recruitment, assessment/diagnostic procedures, treatment protocols, and the generalizability of results from research settings to naturalistic treatment contexts; they rated the clinical representativeness of existing couple therapy outcome studies as only fair. Thus, little is known about change processes in couple therapy conducted within naturalistic treatment contexts.

\section{Interplay of Relationship Adjustment and Individual Functioning Change Processes}

Whether relationship improvement precedes improvement in individuals' mental health, or vice versa, is a fundamental question for psychotherapy. From an individualistic perspective, one might expect that people have to heal themselves first before their relationship can improve, consistent with the medical model view of adult psychopathology (Baucom et al., 2014). In contrast, from a systemic perspective, one would expect that increases in relationship adjustment set the stage for improvement in individual functioning (Fraenkel, 1997). This question, however, remains largely untested by research.

In heterosexual couples, women typically report lower levels of relationship adjustment (e.g., Jackson, Miller, Oka, \& Henry, 2014; Rowe, Doss, Hsueh, Libet, \& Mitchell, 2011) and are more likely to initiate couple therapy (Doss, Atkins, \& Christensen, 2003). With regard to individual functioning, women appear more vulnerable than men to mood and anxiety disorders, whereas men are more likely than women to develop antisocial personality and substance use disorders (e.g., Eaton et al., 2012). These findings raise questions regarding whether men and women benefit from couple therapy in similar or different ways. Although gender has been conceptualized as a major factor in couple therapy (e.g., Knudson-Martin et al., 2015), empirical findings are quite sparse. The only study of couple therapy we could locate which investigated gender differences in the change process showed that men responded to treatment more quickly than did women, 
although their respective amounts of improvement in relationship distress were equivalent at termination (Christensen et al., 2004).

The developmental course of change in response to couple therapy also remains unclear (Doss et al., 2011). For example, little is known about (a) treatment response (i.e., session-by-session changes) in both relationship adjustment and individual functioning; (b) whether these processes differ for men and women; and (c) whether change in relationship adjustment drives change in individual functioning, or vice versa. Investigation of these important questions can inform clinical practice and training by elaborating key processes of change (Snyder \& Whisman, 2003), guiding practitioners' clinical decision making (Lebow et al., 2012), and enhancing outcomes (Pinsof, Goldsmith, \& Latta, 2012). These lines of inquiry also have the potential to bridge the longstanding gap between research and practice (e.g., Kazdin, 2008) by augmenting our sparse knowledge of treatment processes (S. Cohen, O'Leary, Foran, \& Kliem, 2014) and shaping future research on change mechanisms (Rauer et al., 2014).

Within the context of couple therapy, we could locate only two prior studies that evaluated trajectories of change in individual functioning and relationship distress in response to couple therapy. With respect to individual functioning, the clinical trial of integrative behavioral couple therapy (IBCT) and traditional behavioral couple therapy (TBCT) for relationship distress conducted by Christensen et al. (2004) found that individual functioning showed little change; to the extent that individual functioning improved, it changed only as relationship distress improved. With regard to relationship distress, linear increases were detected among couples treated with emotion-focused therapy (Dalgleish et al., 2014) and IBCT (Christensen et al., 2004), whereas a nonlinear pattern of rapid improvement early on in treatment and subsequent stabilization was found in TBCT (Christensen et al., 2004).

In sum, significant uncertainty exists about the nature of conjoint treatment response in relationship adjustment and individual functioning, especially within naturalistic treatment contexts. Key questions left to be answered include the following: What is the shape of change trajectories in relationship adjustment and individual functioning? Do men and women differ in their treatment response? Does change in relationship adjustment precede improvement in individual functioning, or vice versa?

The current study, designed to answer these questions, investigated the process of change within a multisystemic approach to conjoint psychotherapy, integrative problem-centered metaframeworks (IPCM; Breunlin, Pinsof, Russell, \& Lebow, 2011; Pinsof, Breunlin, Chambers, Russell, \& Solomon, 2015; Pinsof, Breunlin, Russell, \& Lebow, 2011). We chose to study IPCM for several reasons: (a) because of its multisystemic, integrative, and problem-centered focus, IPCM's flexibility allows it to draw on interventions designed to promote both individual functioning and relationship adjustment, depending on the couple's presenting problem; (b) as an integrative treatment approach, it is similar to the orientation most commonly practiced by couple and family therapists in applied clinical settings (e.g., Pinsof \& Wynne, 2000), consistent with our focus on external validity; and (c) study therapists (IPCM clinicians from a variety of educational backgrounds, 
experience levels, and disciplines) were drawn from a diverse pool, adding to the generalizability of our results.

Following recommendations by other scholars (e.g., Atkins et al., 2005; Rowe et al., 2011), we measured relationship adjustment and individual functioning broadly, rather than focusing narrowly on relationship distress and symptoms of individual psychopathology. We measured these outcomes before every session, which allowed us to simultaneously model the impact of treatment on men and women, nested within relationships. We examined change processes at the beginning of treatment on the basis of empirical findings showing that initial treatment response is crucial and predicts long-term treatment outcomes (e.g., Stiles et al., 2003; Tang \& DeRubeis, 1999). Building on prior research (Knobloch-Fedders, Pinsof, \& Mann, 2007), we focused on the first eight sessions of therapy.

We examined three research questions (RQs). RQ1 asked how relationship adjustment and individual functioning change during IPCM for both men and women. We expected increases in relationship adjustment, with the most pronounced increases occurring early in treatment; we also explored whether similar increases occurred for individual functioning. RQ2 evaluated whether men and women differ in initial levels or changes in relationship adjustment and individual functioning over time. We expected women to show lower initial levels of relationship adjustment and men to show lower initial levels of individual functioning (Rowe et al., 2011). We also explored gender differences in rates of change in both domains. Finally, RQ3 tested whether change in relationship adjustment precedes change in individual functioning, or vice versa. Following our systemic perspective, we expected change in relationship adjustment to precede change in individual functioning.

\section{Method}

\section{Participants}

Participants were heterosexual couples $(N=125)$ who participated in at least two sessions of conjoint psychotherapy at a large, university-affiliated outpatient clinic specializing in couple and family therapy. At intake, women's mean age was 33.78 years (SD $=9.98$; range: $17-61)$, and men's mean age was 36.08 years ( $S D=10.28$; range: $17-65)$. Seventy-six percent of individuals were Caucasian/White, 8\% Latina/o, 7\% African American/Black, 2\% Asian/Asian American, 2\% biracial, and $5 \%$ other. With respect to marital status, $66 \%$ of couples were married, $7 \%$ cohabiting, $7 \%$ engaged, and $20 \%$ dating. Median annual household income was $\$ 51,500$ (dating/noncohabiting individuals were counted as separate households, whereas cohabiting/married individuals were counted as one household).

Therapists were diverse with respect to training level and discipline. Forty-two percent of couples were treated by full-time licensed therapists with master's or doctoral degrees in clinical or counseling psychology, marriage and family therapy, or social work; $36 \%$ were treated by trainees in master's degree programs in marriage and family therapy or counseling psychology; $19 \%$ were treated by postgraduate clinical fellows; and $3 \%$ were treated by doctoral students in clinical psychology or marriage and family therapy. Therapists' mean age was 36.34 years. Male therapists treated $43 \%$ of couples, and female therapists treated $57 \%$ of couples. Eighty percent of couples 
were treated by Caucasian/White therapists, $12 \%$ by African American/Black therapists, $7 \%$ by Asian/Asian American therapists, and $1 \%$ by biracial therapists.

\section{Treatment Delivery}

Couples sought treatment for a variety of problems, including difficulty with communication, conflict, intimacy, problem solving, parenting, and/or psychopathology in one or both partners. No formal inclusion or exclusion criteria were used with respect to presenting problem or level of distress.

Couples received IPCM (Breunlin et al., 2011; Pinsof et al., 2011; Pinsof, Breunlin, et al., 2015), a multisystemic model of integrative treatment that focuses on changing the couple's presenting problem by using a sequence of interventions drawn from various treatment orientations. Interventions are implemented collaboratively with the couple using a recursive process of hypothesizing (generating a set of theories about the presenting problems and constraints to change), planning (brainstorming possible solutions), conversing (engaging the couple in dialogue, guided by the treatment plan, for the purpose of alleviating constraints to change), and feedback (gathering information about attempts to resolve problems). This therapy process continues until presenting problems are resolved or transformed to the couple's satisfaction (Pinsof et al., 2012).

IPCM's intervention sequence is failure driven: Initially, interventions are drawn from behavioral models of therapy, and they progressively move through cognitive, experiential, biological, familyof-origin, and self-psychology levels of intervention if earlier efforts prove ineffective. Unsuccessful treatment (necessitating a change to the next level of intervention) is an idiographic process, determined by a combination of clinical judgment, discussions with patients regarding a lack of change, and therapist interpretation of patient progress ratings on the Systemic Therapy Inventory of Change (STIC) questionnaire (Pinsof et al., 2009, 2012; Pinsof, Zinbarg, et al., in press).

IPCM is the primary couple therapy treatment approach taught and practiced at the study site. Among the group of therapists who participated in this study, licensed clinicians practice, teach, and/or supervise this approach, and trainees participate in a series of IPCM-based seminars and practica. Because of the naturalistic design of this study, therapist competence and treatment fidelity were not formally assessed.

Treatment was not time limited and ranged from two to 45 sessions. Our initial sample $(N=125)$ consisted of those couples who were present at Sessions 1 and 2 (i.e., completed at least one therapy session in addition to the intake session). A total of 78 couples (62.4\%) attended at least five sessions, and 48 couples (38.4\%) were present at Session 8 . These attrition rates are comparable to those found in other studies of naturally delivered couple therapy (e.g., Mondor et al., 2013; Ward \& McCollum, 2005). Importantly, treatment retention was not related to improvement-neither men's nor women's relationship adjustment or individual functioning at Sessions 1-8 were associated with the number of sessions attended during the study period, with two exceptions (men with higher individual functioning at session 6 and higher relationship adjustment at Session 7 completed more sessions; $p s<.05)$. 
This study was conducted as part of an effort to investigate empirically informed treatment, in which the therapist makes use of patient feedback as treatment unfolds to guide intervention (also called progress research [Pinsof \& Wynne, 2000] or patient-focused research [Lambert, Hansen, \& Finch, 2001]). Providing therapists with feedback on treatment progress has been shown to enhance outcomes compared with no-feedback conditions (Anker, Duncan, \& Sparks, 2009). Couples were informed before beginning treatment that their therapists would have access to their ratings; this methodology differed somewhat from that of previous outcome studies of conjoint therapy, in which therapists were blind to patient progress feedback.

\section{Measures}

Partners independently reported on their relationship adjustment and individual functioning before every session using subscales from the STIC Intersession questionnaire (Pinsof et al., 2009, 2012; Pinsof, Zinbarg, et al., in press). The STIC has been shown to discriminate between a clinical outpatient sample and a nationally representative sample of the U.S. population (Pinsof, Zinbarg, et al., in press); its factor structure and internal reliability has been supported in two outpatient clinical samples and in a nationally representative sample (insof et al., 2009; $\underline{\text { Pinsof, }}$ Zinbarg, et al., in press).

Relationship adjustment was measured using the 10-item Relationship With Partner (RWP) subscale of the STIC, which measures positivity, communication, conflict, trust, and intimacy using a five-point Likert-type response scale. Sample items are "We enjoy doing things together"; "After we hurt each other's feelings, we are good at making up"; and "I am filled with anger towards my partner" (reverse scored). Alphas at all waves ranged between .77 and .88 for women and between .80 and .89 for men. Individual functioning was assessed using the 11-item Individual Problems and Strengths (IPS) subscale of the STIC, which measures mental health symptoms, life skills, and day-to-day functioning on a five-point Likert-type response scale. Sample items are "[I] felt sad most of the day" (reverse scored); "When I get upset, I find healthy ways to make myself feel better"; and "I can speak up for myself when the situation calls for it." Alphas ranged between .75 and .85 for women and between .75 and .85 for men at all waves (except men's Session 8; $\alpha=$ $.64)$.

\section{Results}

\section{Data Analysis Approach}

Data were analyzed using latent growth curve modeling (LGM) within a structural equation modeling framework (e.g., Duncan, Duncan, \& Strycker, 2006). In LGM, change is projected onto two latent variables, a latent intercept (which captures the latent mean of a construct at baseline) and the latent slope (which captures latent change over time). To evaluate overall model fit, we inspected chi-square values (with nonsignificant pvalues indicating satisfactory fit), the comparative fit index (CFI; with values $\geq .95$ indicating satisfactory fit), the Tucker-Lewis index (TLI; with values $\geq .95$ indicating satisfactory fit), and the root mean square error of approximation (RMSEA; with values $\leq .08$ indicating satisfactory fit). 


\section{RQ1}

RQ1 asked how relationship adjustment and individual functioning change during IPCM for both men and women. To test RQ1, we examined changes in men's and women's relationship adjustment and individual functioning over time using piecewise LGM, following Keijsers, Loeber, Branje, and Meeus (2011). Specifically, we estimated latent growth curve models for the initial phase of treatment (Sessions 1-4) and for the subsequent phase of treatment (Sessions 5-8). This piecewise approach was chosen because initial analyses revealed poor fit for simple (i.e., nonpiecewise) linear latent growth curve models that modeled changes over Sessions $1-8, \Delta \chi^{2}(28)$ $=68.14-87.02, p<.001, \mathrm{CFI}=.88-.93, \mathrm{RMSEA}=.108-.130$. Appropriate piecewise latent growth curve models were identified using the following procedure. We started with a linear latent growth curve model with intercept loadings set to $[1 ; 1 ; 1 ; 1]$ and slope loadings set to $[0 ; 1 ; 2 ; 3]$, following recommendations by Coffman and Millsap (2006). When this model did not show good fit, we moved on to a nonlinear latent growth curve model with slope loadings set to [0; free; free; 3]. In a few instances, when there was no significant slope variance, the slope variance was set to 0 , as in prior research (de Frias, Lövdén, Lindenberger, \& Nilsson, 2007). Hypotheses were tested via examination of slope means.

\section{RQ2}

RQ2 evaluated whether men and women differ in initial levels or changes in relationship adjustment and individual functioning over time. To test RQ2, we used the actor-partner interdependence model (Olsen \& Kenny, 2006) and used latent growth curve models for interchangeable dyads, with an adaption to account for dyads distinguishable by gender (e.g., removing equality constraints between men and women; Olsen \& Kenny, 2006). Following analyses for RQ1, we used piecewise LGM. A conceptual dyadic latent growth curve model for men's and women's relationship adjustment across Sessions 1-4 is shown in Figure 1. To test our hypotheses, we compared an unconstrained model with a model in which the intercept or slope means were constrained to be equal for men and women, as recommended (e.g., Duncan et al., 2006). A significant chi-square difference test ( $p s<.05)$ indicated that means differed for men and women. 


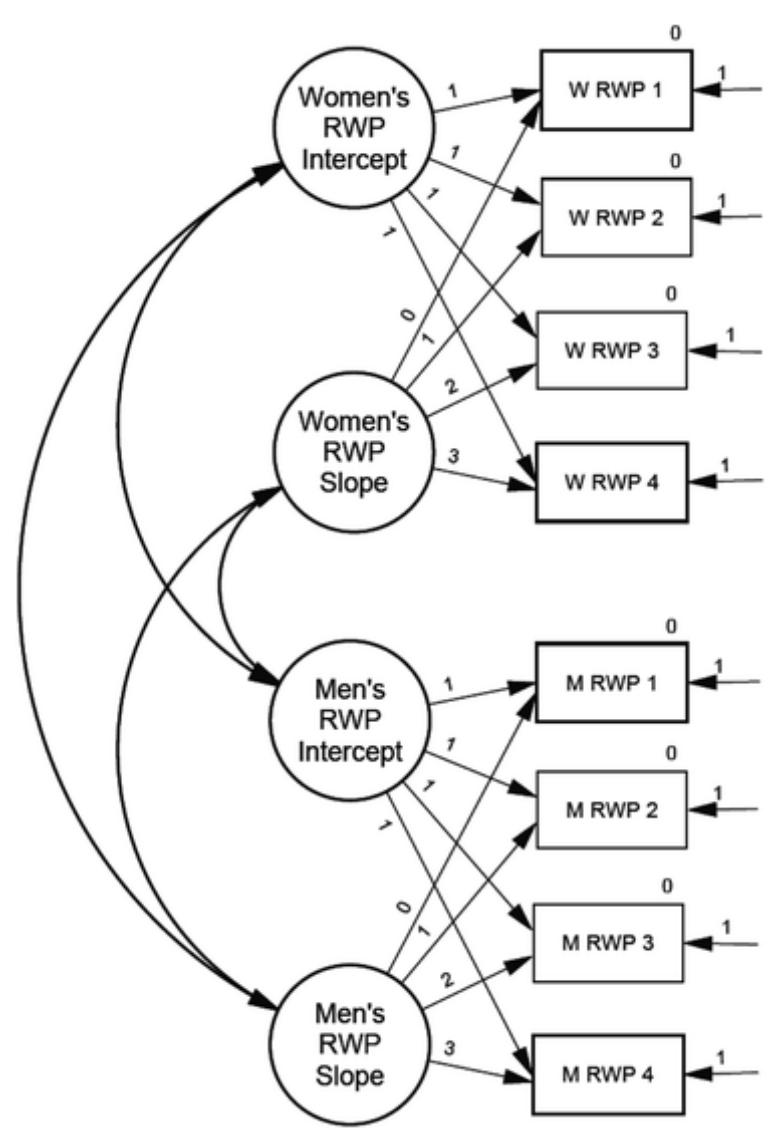

Figure 1. Conceptual dyadic latent growth curve model. This model is based on Olsen and Kenny (2006) and adapted for distinguishable dyads. The figure shows two linear latent growth curve models modeling changes in men's (M) and women's (W) relationship adjustment simultaneously with correlated intercepts and slopes. RWP = Relationship With Partner subscale of the Systemic Therapy Inventory of Change.

\section{RQ3}

RQ3 tested whether change in relationship adjustment precedes change in individual functioning, or vice versa. To test this, we examined cross-lagged associations between relationship adjustment and individual functioning for men and women using cross-lagged path models, including stability effects, correlated changes, and cross-lagged effects (Kline, 2011). Again, similar to the previous analyses, we took a piecewise approach and tested separate cross-lagged models from Sessions 14 and Sessions 5-8. The conceptual cross-lagged model is shown in Figure 2. To test whether crosslagged associations differed across time points, we compared an unconstrained model with a model in which the cross-lagged effects were constrained to be equal across time points (i.e., Sessions 1-2, . . ., Sessions 7-8), as recommended by Duncan et al. (2006). A significant chi-square difference test $(p s<.05)$ indicated that cross-lagged associations differed across time points. 


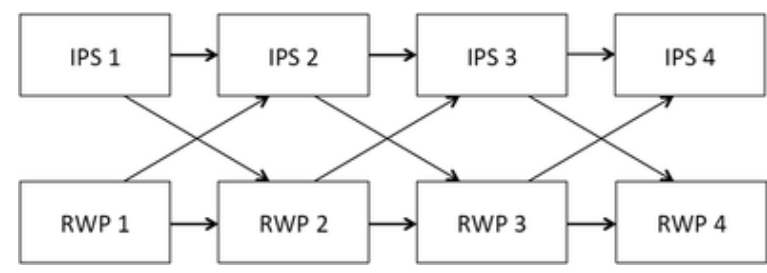

Figure 2. Conceptual cross-lagged model. Individual Problems and Strengths (IPS) and Relationship With Partner (RWP) residuals, intercorrelations between IPS and RWP residuals, and stability paths for IPS and RWP during Sessions 1-4, Sessions 1-3, Sessions 2-3, and Sessions 2-4 were also included in the model but are not shown here.

Preliminary analyses indicated that, for men, cross-lagged effects for Sessions 1-4 were similar across time points, $\Delta \chi^{2}(4)=4.88, p=.300$, so they were constrained to be equal. In contrast, men's cross-lagged effects over Sessions 5-8 were not similar across time points, $\Delta \chi^{2}(4)=10.64, p=.031$, so they were freely estimated. For women, cross-lagged effects over Sessions $1-4, \Delta \chi^{2}(4)=$ $1.44, p=.837$, and over Sessions $5-8, \Delta \chi^{2}(4)=2.60, p=.628$, were similar across time points, so they were constrained to be equal.

Analyses were conducted using AMOS Version 20 (Arbuckle, 2011), which implements a full information maximum likelihood (FIML) algorithm to estimate missing values, one of the "best methods currently available" (Jeličić, Phelps, \& Lerner, 2009, p. 1197). For analyses using data from Sessions 1-4, we included all couples who participated in at least two sessions of therapy $(N=$ 125). For analyses using data from Sessions 5-8, we included all couples who were present at Session $5(n=78)$. When we repeated all analyses using only participants with complete data $(n=$ 48), all results remained stable with two exceptions.

\section{Preliminary Analyses}

Intercorrelations between study variables at Session 1 are displayed in Table 1. Mean levels of relationship adjustment and individual functioning from Sessions 1-8 are presented in Figure 3. As reported by Pinsof, Zinbarg, et al. (in press), values lower than 4.09 (men's and women's RWP), 4.01 (men's IPS), and 3.94 (women's IPS) indicate clinical distress. At pretreatment, both men and women reported clinically significant distress in relationship adjustment $(M=3.67, S D=.59$ [men]; $M=3.50, S D=.58$ [women]) and individual functioning $(M=3.97, S D=.46$ [men]; $M=$ 3.92, $S D=.45$ [women]). In terms of effect sizes (J. Cohen, 1992), moderate increases in relationship adjustment (Cohen's $d s=0.44$ for men and 0.35 for women) and large increases in individual functioning (Cohen's $d s=0.87$ for men and 0.73 for women) were observed between Sessions 1 and 8. With respect to clinical significance (cf. Jacobson \& Truax, 1991), at Session 8, $34.9 \%$ of men and $34.9 \%$ of women had relationship adjustment scores, and $86.0 \%$ of men and $70.5 \%$ of women had individual functioning scores, equal to or higher than the cutoff scores (Pinsof, Zinbarg, et al., in press), indicating clinically significant improvement. 
Table 1

Men's and Women's Relationship Adjustment and Individual

Functioning: Intercorrelations at Pretreatment

\begin{tabular}{lcccc}
\hline \multicolumn{1}{c}{ Variable } & 1 & 2 & 3 & 4 \\
\hline 1. Men's RWP & - & & & \\
2. Women's RWP & $.44^{* * *}$ & - & & \\
3. Men's IPS & $.28^{* *}$ & .17 & - & \\
4. Women's IPS & .13 & $.29^{* *}$ & $.24^{* *}$ & - \\
\hline
\end{tabular}

Note. $\quad N=125$. RWP $=$ Relationship With Partner subscale of the Systemic Therapy Inventory of Change (STIC); IPS = Individual Problems and Strengths subscale of the STIC.

${ }^{*} p<.01 .{ }^{* *} p<.001$.

Table 1. Men's and Women's Relationship Adjustment and Individual Functioning: Intercorrelations at Pretreatment

\begin{tabular}{|l|l|l|l|l|}
\hline Variable & 1 & 2 & 3 & 4 \\
\hline 1. Men's RWP & - & & & \\
\hline 2. Women's RWP & $.44^{* * *}$ & - & & \\
\hline 3. Men's IPS & $.28^{* *}$ & .17 & - & \\
\hline 4. Women's IPS & .13 & $.29^{* *}$ & $.24^{* *}$ & - \\
\hline
\end{tabular}

Note. $\mathrm{N}=125$. RWP = Relationship With Partner subscale of the Systemic Therapy Inventory of Change (STIC); IPS = Individual Problems and Strengths subscale of the STIC.

$* * p<.01 . * * * p<.001$.
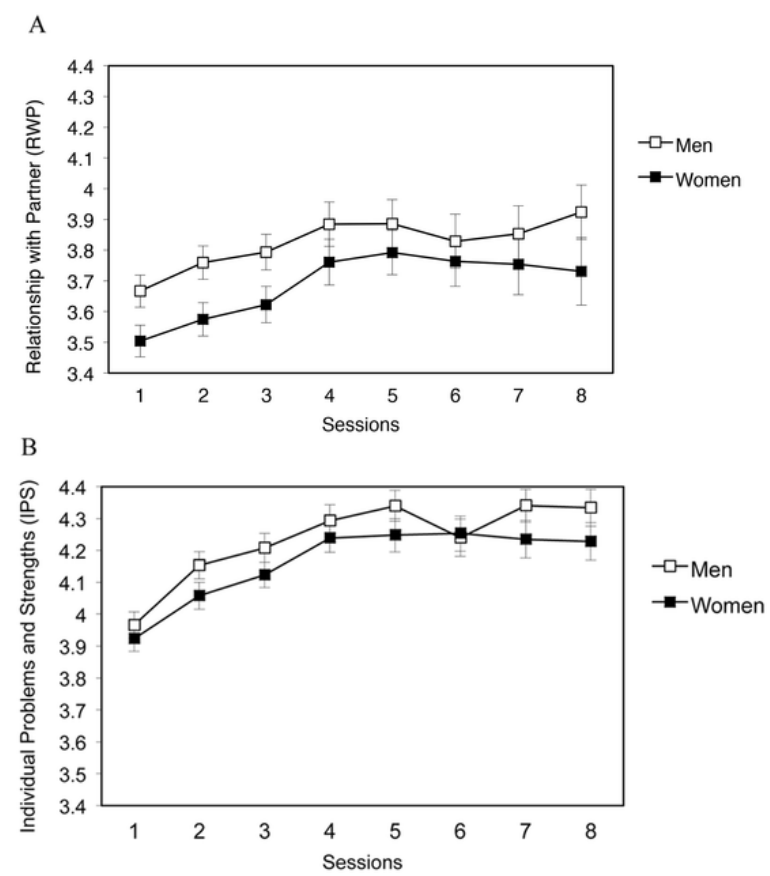

Figure 3. Men's and women's mean relationship adjustment (A) and individual functioning (B) over sessions 1-8. As reported by Pinsof, Zinbarg, et al. (in press), values lower than 4.09 (men's and 
women's RWP), 4.01 (men's IPS), and 3.94 (women's IPS) indicate clinical distress. Error bars represent standard errors of the mean.

\section{Relationship Adjustment and Individual Functioning Treatment Response}

For RQ1, which examined changes in men's and women's relationship adjustment and individual functioning over Sessions 1-8, we used a series of piecewise univariate latent growth curve models. All models showed satisfactory fit (see the note to Table 2). Results indicated nonlinear changes in relationship adjustment and individual functioning; both increased during the first four sessions and stabilized during the subsequent four sessions for men and women. During Sessions $1-4$, relationship adjustment increased for men $(M[$ Slope $]=.06)$ and women $(M[$ Slope $]=.08)$, indicated by positive slope means ( $p s<.001$ ). Similarly, over Sessions $1-4$, individual functioning increased for men $(M[$ Slope $]=.09)$ and women $(M[$ Slope $=.10)$, demonstrated by positive slope means ( $p s<.001$ ). During Sessions 5-8, relationship adjustment and individual functioning remained stable for men and women (nonsignificant slope means; $p s>.05$ ). Exploratory follow-up analyses showed that these change trajectories generalized across a wide range of therapist and patient characteristics.

Table 2

Men's and Women's Relationship Adjustment Over Time:

Piecewise Univariate Latent Growth Curve Models

\begin{tabular}{|c|c|c|c|c|}
\hline \multirow[b]{2}{*}{ Variable } & \multicolumn{2}{|c|}{ Sessions $1-4^{\mathrm{a}}$} & \multicolumn{2}{|c|}{ Sessions $5-8^{\mathrm{b}}$} \\
\hline & Intercept & Slope & Intercept & Slope \\
\hline \multicolumn{5}{|l|}{ Men's RWP } \\
\hline M & $3.68^{* * *}$ & $.06^{\circ *}$ & $3.89^{\circ \cdots *}$ & -.01 \\
\hline$\sigma^{2}$ & $.25^{*+*}$ & .006 & $.37^{* * *}$ & $0^{e}$ \\
\hline \multicolumn{5}{|c|}{ Women's RWP } \\
\hline$M$ & $3.49^{*+*}$ & $.08^{*+4}$ & $3.81^{* * *}$ & -.03 \\
\hline$\sigma^{2}$ & $.21^{* * *}$ & .01 & $.32^{\circ * t}$ & $.01^{\circ}$ \\
\hline \multicolumn{5}{|l|}{ Men's IPS ${ }^{d}$} \\
\hline M & $3.97^{* * 0}$ & $.09^{* *}$ & $4.32^{* * *}$ & -.01 \\
\hline$\sigma^{2}$ & $.17^{* * *}$ & .008 & $.14^{*+*}$ & $.005^{*+}$ \\
\hline \multicolumn{5}{|c|}{ Women's IPS ${ }^{c}$} \\
\hline M & $3.93^{*+*}$ & $.10^{+*+}$ & $4.26^{*+*}$ & .006 \\
\hline$\sigma^{2}$ & $.16^{* \infty}$ & $.008^{\circ}$ & $.17^{\circ * *}$ & .003 \\
\hline
\end{tabular}

Note. $\quad$ RWP $=$ Relationship With Partner subscale of the Systemic Therapy Inventory of Change (STIC); IPS = Individual Problems and Strengths subscale of the STIC. All models showed satisfactory fit (chi-square $p>$ .05 , comparative fit index $\geq .95$, Tucker-Lewis index $\geq .95$, root mean square error of approximation $<.08$ ).

${ }^{\mathrm{a}} N=125$. ${ }^{\mathrm{b}} n=78$. ${ }^{\mathrm{c}}$ Linear latent growth curve models with slope loadings set to $[0 ; 1 ; 2 ; 3]$. ' Unconditional latent growth curve model with slope loadings set [0; free; free; 3$]$, except for men's IPS for sessions $5-8$, for which the linear latent growth curve model had slope loadings set to $[0 ; 1 ; 2 ; 3] . \quad{ }^{e}$ Slope variance set to 0 .

${ }^{*} p<.05 .{ }^{* *} p<.01 .{ }^{* *} p<.001$.

Table 2. Men's and Women's Relationship Adjustment Over Time: Piecewise Univariate Latent Growth Curve Models

\begin{tabular}{|l|l|l|l|l|}
\hline & Sessions 1-4 & & Sessions 5-8 & \\
\hline Variable & Intercept & Slope & Intercept & Slope \\
\hline Men's RWP & & & & \\
\hline
\end{tabular}




\begin{tabular}{|l|l|l|l|l|}
\hline$M$ & $3.68^{* * *}$ & $.06^{* * *}$ & $3.89^{* * *}$ & -.01 \\
\hline$\sigma^{2}$ & $.25^{* * *}$ & .006 & $.37^{* * *}$ & $0^{\mathrm{e}}$ \\
\hline Women's RWP & & & & \\
\hline$M$ & $3.49^{* * *}$ & $.08^{* * *}$ & $3.81^{* * *}$ & -.03 \\
\hline$\sigma^{2}$ & $.21^{* * *}$ & .01 & $.32^{* * *}$ & $.01^{\circ}$ \\
\hline Men's IPS $^{\mathrm{d}}$ & & & & \\
\hline$M$ & $3.97^{* * *}$ & $.09^{* * *}$ & $4.32^{* * *}$ & -.01 \\
\hline$\sigma^{2}$ & $.17^{* * *}$ & .008 & $.14^{* * *}$ & $.005^{* *}$ \\
\hline Women's IPSc & & & & \\
\hline$M$ & $3.93^{* * *}$ & $.10^{* * *}$ & $4.26^{* * *}$ & .006 \\
\hline$\sigma^{2}$ & $.16^{* * *}$ & $.008^{*}$ & $.17^{* * *}$ & .003 \\
\hline
\end{tabular}

Note. RWP = Relationship With Partner subscale of the Systemic Therapy Inventory of Change (STIC); IPS = Individual Problems and Strengths subscale of the STIC. All models showed satisfactory fit (chi-square $p>.05$, comparative fit index $\geq .95$, Tucker-Lewis index $\geq .95$, root mean square error of approximation $<.08$ ).

${ }^{\mathrm{a}} N=125 .{ }^{\mathrm{b}} n=78 .{ }^{\mathrm{c}}$ Linear latent growth curve models with slope loadings set to $[0 ; 1 ; 2 ; 3] .{ }^{\mathrm{d}}$ Unconditional latent growth curve model with slope loadings set [0; free; free; 3], except for men's IPS for sessions 5-8, for which the linear latent growth curve model had slope loadings set to $[0 ; 1 ; 2 ; 3]$. ${ }^{\text {e }}$ Slope variance set to 0 .

$* p_{-}<.05 . * * p<.01 . * * * p<.001$.

\section{Gender Differences in Initial Levels and Changes in Relationship Adjustment and Individual Functioning}

For RQ2, we examined whether men and women differed in initial levels or changes in relationship adjustment and individual functioning (see Table 3 ) using piecewise dyadic latent growth curve models (cf. Figure 1). All models showed satisfactory fit (see the note to Table 3 ).

Table 3

Men's and Women's Relationship Adjustment and Individual Functioning Over Time: Piecewise Dyadic Latent Growth Curve Models

\begin{tabular}{|c|c|c|c|c|c|c|c|c|}
\hline \multirow[b]{3}{*}{ Variable } & \multicolumn{4}{|c|}{ Sessions $1-4^{\mathrm{a}}$} & \multicolumn{4}{|c|}{ Sessions $5-8^{b}$} \\
\hline & \multicolumn{2}{|c|}{ Intercept } & \multicolumn{2}{|c|}{ Slope } & \multicolumn{2}{|c|}{ Intercept } & \multicolumn{2}{|c|}{ Slope } \\
\hline & Men & Women & Men & Women & Men & Women & Men & Women \\
\hline \multicolumn{9}{|l|}{ RWP } \\
\hline$M$ & $3.67^{* \cdots e c}$ & $3.49^{* * c}$ & $.06^{* * *}$ & $.08^{* * *}$ & $3.87^{\circ *}$ & $3.81^{\cdots * *}$ & -.004 & -.03 \\
\hline$\sigma^{2}$ & $.26^{\circ * *}$ & $.23^{* * *}$ & $.008^{*}$ & $.015^{* *}$ & $.38^{* * *}$ & $.35^{* * *}$ & $0^{\mathrm{d}}$ & $.017^{* *}$ \\
\hline \multicolumn{9}{|l|}{ IPS } \\
\hline$M$ & $3.97^{* * *}$ & $3.93^{* * *}$ & $.09^{* * \bullet}$ & $.10^{* * *}$ & $4.32^{* * *}$ & $4.26^{* * 0}$ & -.01 & .008 \\
\hline$\sigma^{2}$ & $.14^{* * *}$ & $.14^{* * *}$ & .005 & .004 & $.14^{* * *}$ & $.16^{* * *}$ & $.004^{* *}$ & $0^{\mathrm{d}}$ \\
\hline
\end{tabular}

Note. Results are shown from separate piecewise latent growth curve models for relationship adjustment and individual functioning. All models showed satisfactory fit (chi-square $p>.05$, comparative fit index $\geq .95$, Tucker-Lewis index $\geq .95$, root mean square error of approximation $<.08$ ). RWP $=$ Relationship With Partner subscale of the Systemic Therapy Inventory of Change (STIC); IPS = Individual Problems and Strengths subscale of the STIC,

${ }^{\mathrm{a}} N=125 .{ }^{\mathrm{b}} n=78 . \quad{ }^{\mathrm{c}}$ Latent means differ at $p<.01 . \quad{ }^{\mathrm{d}}$ Slope variance set to 0 .

${ }^{*} p<.05 .{ }^{* *} p<.01 .{ }^{* *} p<.001$.

Table 3. Men's and Women's Relationship Adjustment and Individual Functioning Over Time: Piecewise Dyadic Latent Growth Curve Models

\begin{tabular}{|l|l|l|l|l|l|l|l|l|}
\hline & & $\begin{array}{l}\text { Sessions } \\
1-4 a\end{array}$ & & & & $\begin{array}{l}\text { Sessions } \\
5-8 \mathrm{~b}\end{array}$ & & \\
\hline & Intercept & & Slope & & Intercept & & Slope & \\
\hline Variable & Men & Women & Men & Women & Men & Women & Men & Women \\
\hline RWP & & & & & & & & \\
\hline M & $3.67^{* * * c}$ & $3.49^{* * * c}$ & $.06^{* * *}$ & $.08^{* * *}$ & $3.87^{* * *}$ & $3.81^{* * *}$ & -.004 & -.03 \\
\hline$\sigma^{2}$ & $.26^{* * *}$ & $.23^{* * *}$ & $.008^{*}$ & $.015^{* *}$ & $.38^{* * *}$ & $.35^{* * *}$ & $0^{\text {d }}$ & $.017^{* *}$ \\
\hline
\end{tabular}




\begin{tabular}{|l|l|l|l|l|l|l|l|l|}
\hline IPS & & & & & & & & \\
\hline $\mathrm{M}$ & $3.97^{* * *}$ & $3.93^{* * *}$ & $.09^{* * *}$ & $.10^{* * *}$ & $4.32^{* * *}$ & $4.26^{* * *}$ & -.01 & .008 \\
\hline$\sigma^{2}$ & $.14^{* * *}$ & $.14^{* * *}$ & .005 & .004 & $.14^{* * *}$ & $.16^{* * *}$ & $.004^{* *}$ & $0^{d}$ \\
\hline
\end{tabular}

Note. Results are shown from separate piecewise latent growth curve models for relationship adjustment and individual functioning. All models showed satisfactory fit (chi-square $p>.05$, comparative fit index $>$ .95 , Tucker-Lewis index $>.95$, root mean square error of approximation $<.08)$. RWP $=$ Relationship With Partner subscale of the Systemic Therapy Inventory of Change (STIC); IPS = Individual Problems and Strengths subscale of the STIC. ${ }^{a} N=125 .{ }^{\mathrm{b}} n=78$. ${ }^{\mathrm{c}}$ Latent means differ at $p<.01 .{ }^{\mathrm{d}}$ Slope variance set to 0 . ${ }^{*} p<.05 .{ }^{* *} p<.01 .{ }^{* * *} p<.001$.

\section{Intercorrelations}

First, we inspected intercorrelations between relationship adjustment and individual functioning intercepts and slopes with a focus on Sessions 1-4 (because the univariate analyses indicated that change in both domains stabilized during subsequent sessions). Relationship adjustment intercepts $(r=.60, p<.001)$ and slopes $(r=.87, p=.001)$ and individual functioning intercepts $(r=.31, p=$ $.005)$ and slopes $(r=.95, p=.008)$ were moderately to highly correlated, indicating substantial cross-partner associations.

\section{Relationship adjustment}

In spite of the high degree of correlation between men's and women's initial levels of relationship adjustment, inferential statistics indicated that men ( $M[$ Intercept $]=3.67$ ) were significantly more likely to enter treatment with a higher level of relationship adjustment than were women $(M[$ Intercept $]=3.49), \Delta \chi^{2}(1)=11.67, p=.001$. However, no differences were detected in men's and women's relationship adjustment change trajectories over time. Although during Sessions 1-4, men $(M[$ Slope $]=.06)$ experienced slightly smaller increases in relationship adjustment than did women $(M[S l o p e]=.08)$, when their two slopes from Sessions 1-4 were compared, the difference in their rates of change was not significant, $\Delta \chi^{2}(1)=1.54, p=.215$. By Session 5 , men and women no longer differed in relationship adjustment, $\Delta \chi^{2}(1)=0.90, p=.344$, or in how their relationship adjustment changed during Sessions $5-8, \Delta \chi^{2}(1)=1.15, p=.283$.

\section{Individual functioning}

Results indicated no differences between men and women in initial levels or changes in individual functioning. Specifically, men and women did not differ in initial levels of individual functioning at pretreatment, $\Delta \chi^{2}(1)=0.68, p=.411$, or in changes in individual functioning during Sessions 1-4, $\Delta \chi^{2}(1)=0.19, p=.661$. Similarly, men and women did not differ in individual functioning at Session $5, \Delta \chi^{2}(1)=0.73, p=.394$, or in how their individual functioning changed during Sessions $5-8, \Delta \chi^{2}(1)$ $=0.53, p=.468$.

\section{Cross-Lagged Associations Between Relationship Adjustment and Individual}

\section{Functioning}

RQ3 examined whether change in relationship adjustment precedes change in individual functioning (or vice versa) using a series of cross-lagged models for men and women (cf. Figure 2). All models showed satisfactory fit (chi-square $p>.05, \mathrm{CFI} \geq .95, \mathrm{TLI} \geq .95, \mathrm{RMSEA}<.08$ ). 


\section{Intercorrelations}

First, we inspected intercorrelations between relationship adjustment and individual functioning at each time point. Men evidenced significant associations at pretreatment $(r=.28, p=.003)$ and at all subsequent time points (correlated changes ranged between .29 and .53 [ $p<.035]$ and dropped to .26 [ $p=.107]$ at Session 8). Women also showed significant associations at intake $(r=.29, p=$ .002 ) and at all subsequent time points (correlated changes ranged between .42 and .47 [ $p \leq$ $.002])$.

\section{Cross-lagged effects of relationship adjustment on individual functioning}

Results indicated significant cross-lagged effects of relationship adjustment on individual functioning for men but not for women. Specifically, for men, there were significant cross-lagged effects of relationship adjustment on individual functioning from Session 1 to Session 2, Session 2 to Session 3, and Session 3 to Session 4 ( $\beta s=.10-.11, p s=.016)$ and from Session 5 to Session 6 ( $\beta$ $=.24, p=.002)$; cross-lagged effects were not significant for the other time points ( $p s>.05)$. For women, cross-lagged effects of relationship adjustment on individual functioning were not significant (all ps > .05).

\section{Cross-lagged effects of individual functioning on relationship adjustment}

There were no significant cross-lagged effects of individual functioning on relationship adjustment for men or women (all $p s>.05$ ).

\section{Discussion}

This study examined change in relationship adjustment and individual functioning over the first eight sessions of conjoint IPCM conducted within a naturalistic treatment setting. Data were collected before every session from each partner, allowing us to model change simultaneously for men and women, nested within couples. Relationship adjustment and individual functioning showed moderate to high correlations for men, for women, and across time. This converges with a wealth of evidence suggesting that relational and individual pathology are coassociated in general (e.g., Whisman, 2007; Whisman \& Baucom, 2012) and within intervention contexts (e.g., Rowe et al., 2011).

At pretreatment, couples reported clinically significant distress in relationship adjustment and individual functioning. However, considerable positive changes were demonstrated in response to IPCM. Overall, effect sizes for change in relationship adjustment were medium sized $(d s=0.44$ for men and 0.35 for women) and were even more pronounced for individual functioning ( $d s=0.87$ for men and 0.73 for women). These effect sizes are comparable to those found within naturalistic therapy contexts (e.g., Hahlweg \& Klann, 1997; Klann, Hahlweg, Baucom, \& Kroeger, 2011) and are about half as large (or larger) than the effect sizes by which clinical and normal samples differ (RWP: $d=0.85$; IPS: $d=1.22$; Pinsof, Zinbarg, et al., in press).

Increases in relationship adjustment and individual functioning occurred in a nonlinear fashion. For both men and women, relationship adjustment and individual functioning increased during the first four sessions and stabilized during the subsequent four sessions of IPCM. This suggests two distinct treatment phases: initial rapid improvement, followed by subsequent stabilization and 
consolidation of gains. Notably, this same treatment response pattern was detected in TBCT (Christensen et al., 2004). Similar to TBCT, IPCM tends to implement behavioral interventions at the beginning of treatment (Pinsof et al., 2011), which may account for the similarity in these treatments' change trajectories. Of course, it is also possible that the positive changes we observed were attributable not to treatment-specific factors but to nonspecific factors occurring at the couple level (e.g., change happened because both partners decided to address problems in their relationship).

Overall, men and women showed remarkable similarities in their change processes. Although women entered treatment reporting more relationship dysfunction than did men, consistent with previous findings (e.g., Rowe et al., 2011), men and women did not differ in how their relationship adjustment changed over time, nor did they differ in their initial levels or changes over time in individual adjustment. This suggests that, to the extent couples improve within conjoint IPCM, they improve in unison, with similar pathways and rates of change.

With respect to treatment response, does change in relationship satisfaction drive change in individual functioning, or vice versa? Although this may seem like a chicken-and-egg problem, our findings showed clear directionality for men in our sample. Significant cross-lagged effects of relationship adjustment on individual functioning were obtained for men but not for women. In contrast, there were no significant cross-lagged effects of individual functioning on relationship adjustment for men or women. Within the context of conjoint treatment, this implies that, at least for men, change in relationship adjustment is a precursor for change in individual functioning. Moreover, the lack of cross-lagged effects of individual functioning on relationship adjustment underscores the fact that, although couples with impaired individual functioning began treatment more relationally distressed, pretreatment individual functioning was unrelated to change in relationship adjustment over time (Rowe et al., 2011).

\section{Clinical Implications of the Findings}

This study demonstrates the importance of examining processes by which relational and individual pathology respond to couple-based interventions, and further underscores the close link between couples' relationship adjustment and partners' mental health (e.g., Baucom et al., 2014). We found that both relationship adjustment and individual functioning respond well to conjoint IPCM, with the most pronounced changes occurring during the first four sessions, followed by a stabilization period over the next four sessions. On the basis of these results, clinicians are encouraged to monitor couples' response to treatment after four sessions and to consider adjusting their treatment plan if little or no progress has been achieved during this period. If gains have been made, therapists are encouraged to evaluate whether couples' treatment goals have been fully met; if not, IPCM therapists should work to continue their intervention sequence during Sessions 5-8 as appropriate.

Men and women evidenced similar rates and shapes of change within IPCM. Consonant with the treatment's multisystemic focus, IPCM clinicians are encouraged to help couples view both relational and individual problems from a systemic perspective by acknowledging both partners' 
contributions to the couple's difficulties (Breunlin et al., 2011; Pinsof et al., 2011). This may have enhanced the likelihood that couples moved through the change process in parallel.

Finally, we found that for men (but not women), relationship adjustment drives change in individual functioning, cohering with evidence suggesting that men derive more health benefits from marriage than do women (e.g., Wanic \& Kulik, 2011). This implies that when men in distressed relationships also report impairment in individual functioning, it may be more effective (or efficient) for therapists to target relationship distress first, rather than starting with individual functioning in hopes that the relationship will improve. However, women may need an explicit focus on both individual and relationship functioning domains to show improvement in both because of the more relational nature of their self-concepts (Kiecolt-Glaser \& Newton, 2001).

\section{Study Limitations}

Designed as a naturalistic investigation of psychotherapy, our study lacked some of the methodological control typical of clinical trials. Couples sought treatment for a variety of presenting problems at a variety of severity levels, formal inclusion and exclusion criteria were not used, therapists were heterogeneous with respect to training and clinical experience, and treatment adherence was not evaluated. We also did not use a no-treatment control group, limiting our ability to draw causal conclusions. Lack of a control group seemed reasonable, however, in light of meta-analytic results suggesting that relationship distress is an unremitting problem that typically does not improve without treatment (Baucom, Hahlweg, \& Kuschel, 2003). Because our results are not directly comparable with those obtained via clinical trials, however, this is an important next step for future work.

Attrition is a common problem in investigations of naturally occurring couple therapy (e.g., Mondor et al., 2013; Ward \& McCollum, 2005), and our study was no exception. Although attrition was not selective with regard to key study variables, and although we used a recommended approach to estimating missing data (FIML), attrition raises the possibility that observed changes do not generalize to participants who ended treatment before Session 8.

Finally, similar to other studies of couple therapy in naturalistic settings (e.g., Biesen \& Doss, 2013), our sample size $(N=125)$ and the number of sessions examined (eight) were small. Although this design allowed us to use sophisticated statistical modeling approaches (Kline, 2011), future research must examine longer term trajectories and outcomes in larger samples. In addition, although we explored the effects of various therapist and patient characteristics (see Footnote 3 ), data on couples' relationship length was not collected, precluding its use as a covariate.

\section{Implications for Future Research}

Research evaluating the effectiveness of couple therapy in real-world settings is still sparse (Klann et al., 2011), and we, along with other scholars, encourage greater emphasis on effectiveness studies in applied clinical settings (e.g., Baucom et al., 2003; Lebow et al., 2012; Wright et al., 2007). It will be important for future research to examine outcomes through treatment termination, as well as the maintenance of gains after treatment ends, while making strong efforts to minimize attrition. It is also important to examine the impact of conjoint therapy on outcomes 
beyond relationship adjustment and individual functioning, including relationship problems (Lavner, Karney, \& Bradbury, 2014), physical health (Robles, Slatcher, Trombello, \& McGinn, 2014), work satisfaction (Ford, Heinen, \& Langkamer, 2007), and children's adjustment (Reid \& Crisafulli, 1990).

Providing therapists with feedback on treatment progress has been shown to improve couple therapy outcomes (Anker et al., 2009), and therapists in this study received patient feedback and were encouraged to use it to tailor their interventions. Although many therapists do not yet use this type of empirically informed intervention, its use in clinical settings is growing, especially because of health care's increasing focus on measurable outcomes. Therefore, future work evaluating treatment delivery in which therapists make use of patient feedback is important.

\section{Footnotes}

1 However, as is typical in naturalistic treatment contexts, couples with presenting problems judged inappropriate for the outpatient clinic (e.g., domestic violence, psychosis) were referred to alternative treatment services.

$\underline{2}$ First, men showed higher levels of relationship adjustment than did women at Session $5(p<.05)$. Second, the cross-lagged effects of relationship adjustment on individual functioning for men over Sessions 1-4 were nonsignificant because of the lower sample size, but they pointed in a similar direction.

$\underline{3}$ The present study sought to examine average (i.e., mean-level) changes in relationship adjustment and individual functioning. In a series of follow-up analyses, we explored whether these changes generalized across therapist (i.e., age, gender, and experience $[0=$ trainee, 1 = full-time licensed therapist]) and patient (i.e., men's and women's age, gender, income, and marital status [ $0=$ not married, $1=$ married]) characteristics by including these variables as predictors in the univariate latent growth curve models. We used an alpha level of .01 because we did not have a priori hypotheses and conducted a large number of statistical tests. Results showed that, overall, therapist and patient characteristics did not consistently predict (a) initial levels of relationship adjustment and individual functioning (indicated by nonsignificant intercept associations) or (b) change over time (indicated by nonsignificant slope associations). The latter finding indicated that the overall change trajectories we found were quite generalizable (with an interesting exception indicating greater plasticity at younger ages; specifically, lower therapists' age and lower women's age predicted greater increases in individual functioning for women, and lower men's age predicted greater increases in men's relationship adjustment [all $p s<.01$ ]).

\section{References}

Anker, M. G., Duncan, B. L., \& Sparks, J. A. (2009). Using client feedback to improve couple therapy outcomes: A randomized clinical trial in a naturalistic setting. Journal of Consulting and Clinical Psychology, 77, 693-704. 10.1037/a0016062

Arbuckle, J. L. (2011). IBM SPSS Amos 20 user's guide. Armonk, NY: IBM Corp.

Atkins, D. C., Berns, S. B., George, W. H., Doss, B. D., Gattis, K., \& Christensen, A. (2005). Prediction of response to treatment in a randomized clinical trial of marital therapy. Journal of Consulting and Clinical Psychology, 73, 893-903. 10.1037/0022-006X.73.5.893 
Baucom, D. H., Belus, J. M., Adelman, C. B., Fischer, M. S., \& Paprocki, C. (2014). Couple-based interventions for psychopathology: A renewed direction for the field. Family Process, 53, 445-461. 10.1111/famp.12075

Baucom, D. H., Hahlweg, K., \& Kuschel, A. (2003). Are waiting-list control groups needed in future marital therapy outcome research?Behavior Therapy, 34, 179-188. 10.1016/S00057894(03)80012-6

Baucom, D. H., Shoham, V., Mueser, K. T., Daiuto, A. D., \& Stickle, T. R. (1998). Empirically supported couple and family interventions for marital distress and adult mental health problems. Journal of Consulting and Clinical Psychology, 66, 53-88. 10.1037/0022006X.66.1.53

Biesen, J. N., \& Doss, B. D. (2013). Couples' agreement on presenting problems predicts engagement and outcomes in problem-focused couple therapy. Journal of Family Psychology, 27, 658-663. 10.1037/a0033422

Breunlin, D. C., Pinsof, W., Russell, W. P., \& Lebow, J. (2011). Integrative problem-centered metaframeworks therapy I: Core concepts and hypothesizing. Family Process, 50, 293-313. 10.1111/j.1545-5300.2011.01362.x

Christensen, A., Atkins, D. C., Berns, S., Wheeler, J., Baucom, D. H., \& Simpson, L. E. (2004). Traditional versus integrative behavioral couple therapy for significantly and chronically distressed married couples. Journal of Consulting and Clinical Psychology, 72, 176-191. 10.1037/0022-006X.72.2.176

Coffman, D. L., \& Millsap, R. E. (2006). Evaluating latent growth curve models using individual fit statistics. Structural Equation Modeling, 13, 1-27. 10.1207/s15328007sem1301_1

Cohen, J. (1992). A power primer. Psychological Bulletin, 112, 155-159. 10.1037/00332909.112.1.155

Cohen, S., O'Leary, K. D., Foran, H. M., \& Kliem, S. (2014). Mechanisms of change in brief couple therapy for depression. Behavior Therapy, 45, 402-417. 10.1016/j.beth.2014.01.003

Dalgleish, T. L., Johnson, S. M., Burgess Moser, M., Lafontaine, M. F., Wiebe, S. A., \& Tasca, G. A. (2014). Predicting change in marital satisfaction throughout emotionally focused couple therapy. Advance online publication. Journal of Marital and Family Therapy. 10.1111/jmft.12077

Davila, J., Karney, B. R., Hall, T. W., \& Bradbury, T. N. (2003). Depressive symptoms and marital satisfaction: Within-subject associations and the moderating effects of gender and neuroticism. Journal of Family Psychology, 17, 557-570. 10.1037/0893-3200.17.4.557

de Frias, C. M., Lövdén, M., Lindenberger, U., \& Nilsson, L.-G. (2007). Revisiting the dedifferentiation hypothesis with longitudinal multi-cohort data. Intelligence, 35, 381-392. 10.1016/j.intell.2006.07.011

Doss, B. D., Atkins, D. C., \& Christensen, A. (2003). Who's dragging their feet? Husbands and wives seeking marital therapy. Journal of Marital and Family Therapy, 29, 165-177. 10.1111/j.1752-0606.2003.tb01198.x

Doss, B. D., Rowe, L. S., Carhart, K., Madsen, J. W., \& Georgia, E. J. (2011). Sudden gains in treatment-as-usual couple therapy for military veterans. Behavior Therapy, 42, 509-520. 10.1016/j.beth.2010.12.001

Duncan, T. E., Duncan, S. C., \& Strycker, L. A. (2006). An introduction to latent variable growth curve modeling: Concepts, issues, and applications(2nd ed.). Mahwah, NJ: Erlbaum. 
Eaton, N. R., Keyes, K. M., Krueger, R. F., Balsis, S., Skodol, A. E., Markon, K. E., . . Hasin, D. S. (2012). An invariant dimensional liability model of gender differences in mental disorder prevalence: Evidence from a national sample. Journal of Abnormal Psychology, 121, 282288. 10.1037/a0024780

Ford, M. T., Heinen, B. A., \& Langkamer, K. L. (2007). Work and family satisfaction and conflict: A meta-analysis of cross-domain relations. Journal of Applied Psychology, 92, 57-80.

Fraenkel, P. (1997). Systems approaches to couple therapy. In W.Halford \& H.Markman (Eds.), Clinical handbook of marital and couples interventions(pp. 379-413). New York, NY: Wiley.

Hahlweg, K., \& Klann, N. (1997). The effectiveness of marital counseling in Germany: A contribution to health services research. Journal of Family Psychology, 11, 410-421. 10.1037/0893-3200.11.4.410-421

Jackson, J. B., Miller, R. B., Oka, M., \& Henry, R. G. (2014). Gender differences in marital satisfaction: A meta-analysis. Journal of Marriage and the Family, 76, 105-129. 10.1111/jomf.12077

Jacobson, N. S., \& Truax, P. (1991). Clinical significance: A statistical approach to defining meaningful change in psychotherapy research. Journal of Consulting and Clinical Psychology, 59, 12-19. 10.1037/0022-006X.59.1.12

Jeličić, H., Phelps, E., \& Lerner, R. M. (2009). Use of missing data methods in longitudinal studies: The persistence of bad practices in developmental psychology. Developmental Psychology, 45, 1195-1199. 10.1037/a0015665

Kazdin, A. E. (2008). Evidence-based treatment and practice: New opportunities to bridge clinical research and practice, enhance the knowledge base, and improve patient care. American Psychologist, 63, 146-159. 10.1037/0003-066X.63.3.146

Keijsers, L., Loeber, R., Branje, S., \& Meeus, W. (2011). Bidirectional links and concurrent development of parent-child relationships and boys' offending behavior. Journal of Abnormal Psychology, 120, 878-889. 10.1037/a0024588

Kiecolt-Glaser, J. K., \& Newton, T. L. (2001). Marriage and health: His and hers. Psychological Bulletin, 127, 472-503. 10.1037/0033-2909.127.4.472

Klann, N., Hahlweg, K., Baucom, D. H., \& Kroeger, C. (2011). The effectiveness of couple therapy in Germany: A replication study. Journal of Marital and Family Therapy, 37, 200-208. 10.1111/j.1752-0606.2009.00164.x

Kline, R. B. (2011). Principles and practices of structural equation modeling(3rd ed.). New York, NY: Guilford Press.

Knobloch-Fedders, L. M., Pinsof, W. M., \& Mann, B. J. (2007). Therapeutic alliance and treatment progress in couple psychotherapy. Journal of Marital and Family Therapy, 33, 245-257. 10.1111/j.1752-0606.2007.00019.x

Knudson-Martin, C., Huenergardt, D., Lafontant, K., Bishop, L., Schaepper, J., \& Wells, M. (2015). Competencies for addressing gender and power in couple therapy: A socio emotional approach. Journal of Marital and Family Therapy, 41, 205-220. 10.1111/jmft.12068

Lambert, M. J., Hansen, N. B., \& Finch, A. E. (2001). Patient-focused research: Using patient outcome data to enhance treatment effects. Journal of Consulting and Clinical Psychology, 69, 159-172. 10.1037/0022-006X.69.2.159 
Lavner, J. A., Karney, B. R., \& Bradbury, T. N. (2014). Relationship problems over the early years of marriage: Stability or change?Journal of Family Psychology, 28, 979-985.

10.1037/a0037752

Lebow, J. L., Chambers, A. L., Christensen, A., \& Johnson, S. M. (2012). Research on the treatment of couple distress. Journal of Marital and Family Therapy, 38, 145-168. 10.1111/j.17520606.2011.00249.x

Mondor, J., Sabourin, S., Wright, J., Poitras-Wright, H., McDuff, P., \& Lussier, Y. (2013). Early termination from couple therapy in a naturalistic setting: The role of therapeutic mandates and romantic attachment. Contemporary Family Therapy, 35, 59-73. 10.1007/s10591-0129229-z

Olsen, J. A., \& Kenny, D. A. (2006). Structural equation modeling with interchangeable dyads. Psychological Methods, 11, 127-141. 10.1037/1082-989X.11.2.127

Pinsof, W. M., Breunlin, D. C., Chambers, A. L., Solomon, A. H., \& Russell, W. P. (2015). Integrative, multi-systemic and empirically informed couple therapy: The IPCM perspective. In A.Gurman, J.Lebow, \& D. K.Snyder (Eds.), Clinical handbook of couple therapy (5th ed., pp. 161-191). New York, NY: Guilford Press.

Pinsof, W., Breunlin, D. C., Russell, W. P., \& Lebow, J. (2011). Integrative problem-centered metaframeworks therapy II: Planning, conversing, and reading feedback. Family Process, 50, 314-336. 10.1111/j.1545-5300.2011.01361.x

Pinsof, W. M., Goldsmith, J. Z., \& Latta, T. A. (2012). Information technology and feedback research can bridge the scientist-practitioner gap: A couple therapy example. Couple and Family Psychology: Research and Practice, 1, 253-273. 10.1037/a0031023

Pinsof, W. M., \& Wynne, L. C. (2000). Toward progress research: Closing the gap between family therapy practice and research. Journal of Marital and Family Therapy, 26, 1-8. 10.1111/j.1752-0606.2000.tb00270.x

Pinsof, W. M., Zinbarg, R. E., Lebow, J. L., Knobloch-Fedders, L. M., Durbin, E., Chambers, A., . . .Friedman, G. (2009). Laying the foundation for progress research in family, couple, and individual therapy: The development and psychometric features of the initial systemic therapy inventory of change. Psychotherapy Research, 19, 143-156. 10.1080/10503300802669973

Pinsof, W. M., Zinbarg, R. E., Shimokawa, K., Latta, T. A., Goldsmith, J. Z., Knobloch-Fedders, L. M., ... .Lebow, J. L. (in press). Confirming, validating, and norming the factor structure of the Systemic Therapy Inventory of Change Initial and Intersession. Family Process.

Rauer, A. J., Adler-Baeder, F., Lucier-Greer, M., Skuban, E., Ketring, S. A., \& Smith, T. (2014). Exploring processes of change in couple relationship education: Predictors of change in relationship quality. Journal of Family Psychology, 28, 65-76. 10.1037/a0035502

Reid, W. J., \& Crisafulli, A. (1990). Marital discord and child behavior problems: A metaanalysis. Journal of Abnormal Child Psychology, 18, 105-117. 10.1007/BF00919459

Robles, T. F., Slatcher, R. B., Trombello, J. M., \& McGinn, M. M. (2014). Marital quality and health: A meta-analytic review. Psychological Bulletin, 140, 140-187. 10.1037/a0031859

Rowe, L. S., Doss, B. D., Hsueh, A. C., Libet, J., \& Mitchell, A. E. (2011). Coexisting difficulties and couple therapy outcomes: Psychopathology and intimate partner violence. Journal of Family Psychology, 25, 455-458. 10.1037/a0023696 
Snyder, D. A., \& Whisman, M. K. (2003). Understanding psychopathology and couple dysfunction: Implications for clinical practice, training, and research. In D. A.Snyder \& M. K. Whisman (Eds.), Treating difficult couples: Helping clients with coexisting mental and relationship disorders (pp. 419-438). New York, NY: Guilford Press.

Stiles, W. B., Leach, C., Barkham, M., Lucock, M., Iveson, S., Shapiro, D. A., . . Hardy, G. E. (2003). Early sudden gains in psychotherapy under routine clinic conditions: Practice-based evidence. Journal of Consulting and Clinical Psychology, 71, 14-21.

Tang, T. Z., \& DeRubeis, R. J. (1999). Reconsidering rapid early response in cognitive behavioral therapy for depression. Clinical Psychology: Science and Practice, 6, 283-288. 10.1093/clipsy.6.3.283

Villeneuve, L., Trudel, G., Dargis, L., Préville, M., Boyer, R., \& Bégin, J. (2014). Marital functioning and psychological distress among older couples over an 18-month period. Journal of Sex \& Marital Therapy, 40, 193-208. 10.1080/0092623X.2012.736919

Wanic, R., \& Kulik, J. (2011). Toward an understanding of gender differences in the impact of marital conflict on health. Sex Roles, 65, 297-312. 10.1007/s11199-011-9968-6

Ward, D. B., \& McCollum, E. E. (2005). Treatment effectiveness and its correlates in a marriage and family therapy training clinic. American Journal of Family Therapy, 33, 207-223. 10.1080/01926180590932960

Whisman, M. A. (2007). Marital distress and DSM-IV psychiatric disorders in a population-based national survey. Journal of Abnormal Psychology, 116, 638-643. 10.1037/0021843X.116.3.638

Whisman, M. A., \& Baucom, D. H. (2012). Intimate relationships and psychopathology. Clinical Child and Family Psychology Review, 15, 4-13. 10.1007/s10567-011-0107-2

Whisman, M. A., \& Uebelacker, L. A. (2006). Impairment and distress associated with relationship discord in a national sample of married or cohabiting adults. Journal of Family

Psychology, 20, 369-377. 10.1037/0893-3200.20.3.369

Whisman, M. A., Uebelacker, L. A., \& Weinstock, L. M. (2004). Psychopathology and marital satisfaction: The importance of evaluating both partners. Journal of Consulting and Clinical Psychology, 72, 830-838. 10.1037/0022-006X.72.5.830

Wright, J., Sabourin, S., Mondor, J., McDuff, P., \& Mamodhoussen, S. (2007). The clinical representativeness of couple therapy outcome research. Family Process, 46, 301-316. 10.1111/j.1545-5300.2007.00213.x

Submitted: October 12, 2014 Revised: June 14, 2015 Accepted: June 15, 2015

This publication is protected by US and international copyright laws and its content may not be copied without the copyright holders express written permission except for the print or download capabilities of the retrieval software used for access. This content is intended solely for the use of the individual user.

Source: Journal of Family Psychology. Vol. 29. (5), Oct, 2015 pp. 657-666)

Accession Number: 2015-36858-001

Digital Object Identifier: 10.1037/fam0000131 